Open Access

\title{
Whether profitability and investment factors have additional explanatory power comparing with Fama-French Three-Factor Model: empirical evidence on Chinese A- share stock market
}

\author{
Wenting Jiao *iD and Jean-Jacques Lilti
}

\author{
* Correspondence: \\ wentingjiao@hotmail.com \\ IGR-IAE Université de Rennes 1, 11 \\ rue Jean Macé CS 70803, 35708 \\ Rennes Cedex 7, France
}

\begin{abstract}
Background: Fama and French propose a five-factor model that contains the market factor and factors related to size, book-to-market equity ratio, profitability, and investment, which outperforms the Fama-French Three-Factor Model in their paper in 2014. This study investigates the performance of Fama-French Five-Factor Model and compare with that of Fama-French Three-Factor Model on Chinese Ashare stock market.

Methods: Portfolios are constructed following Fama and French method. The OLS is applied to running time-series regressions; the t-statistics of regression coefficients are corrected for heteroscedasticity and autocorrelation using the Newey-West estimator with five lags.

Results: The empirical results show that Fama-French Five-Factor Model explanatory power has differences among different sets of portfolios. In comparison with FamaFrench Three-Factor Model, the presence of profitability and investment factors seem not to capture more variations of expected stock returns than the three-factor model except for six value-weighted portfolios formed on size and operating profitability.

Conclusions: Profitability and investment factors do not have much additional explanatory power, and Fama-French Five-Factor Model does not have significant improvement in explaining average excess stock returns comparing with the original three-factor model on Chinese A-share stock market, which is inconsistent with the findings on US stock market.
\end{abstract}

Keywords: Profitability factor, Investment factor, Fama-French Five-Factor Model, Chinese A-share stock market

\section{Background}

Fama and French (1993) propose a three-factor model including a size factor (SMB) and book-to-market equity factor (HML) in addition to market beta, which captures the cross-sectional variation in average stock returns. That is the famous Fama-French Three-Factor Model (FF3F Model hereafter). According to Fama and French (FF hereafter), firm size and book-to-market equity ratio are related to the systematic pattern of

(c) The Author(s). 2017 Open Access This article is distributed under the terms of the Creative Commons Attribution 4.0 International License (http://creativecommons.org/licenses/by/4.0/), which permits unrestricted use, distribution, and reproduction in any medium, provided you give appropriate credit to the original author(s) and the source, provide a link to the Creative Commons license, and indicate if changes were made. 
profitability and growth. They are potentially major sources of risk in return. These two mentioned variables are known in most studies as two specific market indicators that raise questions about the model. These findings diminished the credence of this model, and a new wave was formed in the development field of financial theories with the aim of explaining the causes of these special consequences.

Fama and French (2006) have studied for the three variables, book-to-market (B/M) ratio, profitability, and investment effects, which are related to expected stock returns according to the dividend discount model and the valuation equation. They confirm the implies of valuation theory that high rates of investment are related to low expected returns when controlling $\mathrm{B} / \mathrm{M}$ ratio and profitability, while controlling two other variables, high profitable stocks have higher expected stock returns.

Novy-Marx (2013) uncovers a positive relationship between profitable firms and expected returns. Haugen and Baker (1996) and Cohen et al. (2002) find that, controlling for book-to-market equity, average returns are positively related to profitability. Fairfield et al. (2003), Richardson and Sloan (2003), and Titman et al. (2004) show a negative relation between average returns and investment.

Especially, Hou et al. (2015) examine nearly 80 anomalies in the literatures from January 1972 to December 2012 on US market based on q theory, but about one-half of the anomalies seems to exaggerate their explaining power for average stock returns. They come to a conclusion that a four-factor model which includes the market factor, size factor, profitability factor, and investment factor explains the cross-sectional average stock returns to a large extent and outperforms the FF3F Model and Carhart (1997) four-factor model.

Motivated by the "Dividend Discount Model" and recent empirical findings on the strong profitability and investment effects in asset returns ${ }^{1}$, Fama and French (2014) propose a five-factor model that contains the market factor and factors related to size, book-to-market equity ratio, profitability, and investment and test the performance of the five-factor model on the US market using the data from July 1963 to December 2013. They use three sets of factors ${ }^{2}$ in order to examine whether the specifics of factor construction do have important impact on the results of the test of asset pricing models.

Their results suggest that a five-factor model performs better than the three-factor model of Fama and French (1993). But the five-factor model fails to capture low-average returns on small stocks with high investment and low profitability. They also show that the model's performance is not affected by the way the factors are calculated. With two additional factors, their results also suggest that the value factor (HML) becomes redundant.

There is not much research on Fama-French Five-Factor Model (FF5F Model hereafter) outside of US market. For instance, Fama and French (2015) perform the international tests of FF5F Model in North America, Europe, Japan, and Asia Pacific. Expected stock returns increase with the $\mathrm{B} / \mathrm{M}$ ratio and profitability and decrease with investment for North America, Europe, and Asia Pacific; however, the average stock returns show little relation to profitability or investment factors.

Martinsa and Eid Jr (2015) test the performance of FF5F Model on Brazilian market and find that FF5F Model performs better than their previous work in three-factor model. The market factor, SMB, and HML capture most of the variations of average expected excess returns in the time-series regressions; however, the profitability and investment factors have shown less explanatory power. Chiah et al. (2015) investigate the FF5F Model on Australia 
market, and the results indicate that the profitability and investment factors have significantly positive premium. FF5F Model proved to be able to explain average stock returns better than FF3F Model in Australia; in contrary to Fama and French (2014) results, the value factor (HML) remains its explanatory power in the presence of the investment and profitability factors.

To the best of our knowledge, many literatures (such as Drew et al. (2003), Eun and Huang (2007), Wang and Di Iorio (2007) and Chen et al. (2015), etc. ) have examined the ability of FF3F Model in predicting the movements of stock price in China. However, there is no such a work of applying FF5F Model on Chinese stock market so far. This study constructs the profitability and investment factors and explores the Fama-French Five-Factor Model on Chinese A-share stock market, providing the latest evidence of factor model and an update to the existing asset pricing literature on Chinese stock market. In addition, we compare the performance of FF5F Model and FF3F Model on Chinese A-share stock market; furthermore, we compare the empirical results between Chinese and US stock market over the same time interval.

Following, we begin with a brief introduction of Chinese special features. The Data and Methodology section describe the data and construction of FF five factors and three sets of portfolios. The empirical results on Chinese stock market are presented in the Results section, while the empirical results of FF5F Model on US stock market are shown in the Fama-French Five-Factor Model on US stock market section. In the Discussion section, we provide direction for further research. Conclusions of this study are in the Conclusions section.

\section{Special features of Chinese stock market}

The emerging empirical literatures suggest that Chinese market has some special features, and it is inevitable to consider those special features if researchers want to have more accurate empirical results in China. As such, Zhan-hui (2004), Zhang and Xu (2013), and Hung et al. (2015) implement their researches considering one or several special features on Chinese stock market. We summarize two primary features which are also most frequently employed by literatures.

Tradable and non-tradable shares: it is well known that China have substantial holdings of non-traded shares which means that these shares are not effectively valued. Before April 2005, listed companies had two kinds of shares outstanding which are tradable shares and non-tradable shares (held by government agencies or government-related enterprises and were non-tradable in the public market). Chinese government started the share-structure reform in April 2005 to legally convert non-tradable shares to tradable shares. Almost all Chinese listed companies completed the reform by the end of 2006. Using only tradable shares to value weight stock returns is the right way to proceed.

Segmentation of Chinese stock market: more than 170 Chinese listed firms have issued multiple class shares which have the same cash flow and voting rights but are traded in different markets. Some of them have A-shares and B-shares, some have A-shares and $\mathrm{H}$-shares, and others have the A-shares and shares in other foreign markets. Since these shares share the same cash flow and voting rights, they usually have the same claim on the firm's book value of equity. Our research focuses only on the Chinese A-share stock market, in order to obtain the book-to-market equity ratio per A-share of a company with multiple class shares; it is incorrect to divide the firm's total book value equity from its balance sheet 
by the total market value. Instead, the correct way is to calculate the book value equity per share divided by the A-share price.

On account of the special features of Chinese stock market, the value-weighted stocks are constructed using their tradable shares, and book-to-price $(\mathrm{B} / \mathrm{P})$ ratio is used instead of $\mathrm{B} / \mathrm{M}$ ratio in this study.

\section{Methods}

Data

Chinese A-share stocks contain both A-share stocks of Shanghai Stock Exchange (SSE) and Shenzhen Stock Exchange (SZSE). We choose all the firms on Chinese A-share stock market excluding financial firms and firms with negative $\mathrm{B} / \mathrm{P}$ ratio. In addition, a firm is eliminated if the relevant information is missing in a particular month or period and the obvious errors are corrected manually.

For the period of July 2010 to May 2015 (59 months), monthly index prices and stock prices are obtained from Bloomberg, so as to their market capitalization, book value per share, total shares outstanding, and listed shares outstanding. Furthermore, riskfree rate (RF rate) is a typical proxy for the return on a 1-month Treasury bill. But in China, the 1-month Treasury bill has never been issued until February 2007. To keep it consistent with our sample period, we replace it with "Three-Month Treasury Bill Rate (3M rate)" and the 1-month risk-free rate is then equal to the $3 \mathrm{M}$ rate divided by three.

\section{Construction of Fama-French five factors}

Fama and French (2014) Five-Factor Model contains the market factor and factors related to size, book-to-market equity ratio, profitability, and investment:

$$
R_{i, t}-R_{f}=a_{i}+b_{i}\left(R_{M, t}-R_{f}\right)+s_{i} \mathrm{SMB}+h_{i} \mathrm{HML}+r_{i} \mathrm{RMW}+c_{i} \mathrm{CMA}+e_{i, t}
$$

Where $R_{i, t}-R_{f}$ is the excess returns of portfolio $i$ at time $t ; a$ is the constant; $b, s, h, r$, and $c$ are respectively the coefficient for corresponding factors; $e$ is the error term; $R_{M, t}$ $-R_{f}$ is the excess market returns (market factor); SMB and HML are factors related to size and $\mathrm{B} / \mathrm{P}$ ratio, while RMW is the factor related to firm's profitability which is the difference between the returns on portfolios of robust (high) profitability and weak (low) profitability firms; and CMA is the one related to investment, which is the difference between the returns of conservative (low) investment portfolios and aggressive (high) investment portfolios.

Table 1 shows the annual number of firms that have available data of firm size, B/P ratio, operating profitability (OP), and investment (Inv) on Chinese A-share stock market. The OP numbers are always less available than Inv numbers, and there are even few (less than 30) available OP numbers before 2009. To be more accurate and reduce

Table 1 Annual firm numbers which have available data of size, B/P ratio, OP, and Inv

\begin{tabular}{llllllllllll}
\hline Year & 2004 & 2005 & 2006 & 2007 & 2008 & 2009 & 2010 & 2011 & 2012 & 2013 & 2014 \\
\hline Size & 1105 & 1158 & 1175 & 1254 & 1352 & 1408 & 1662 & 1977 & 2189 & 2248 & 2224 \\
B/P & 929 & 1020 & 1008 & 1106 & 1218 & 1286 & 1500 & 1846 & 2069 & 2110 & 2040 \\
OP & 12 & 17 & 24 & 26 & 27 & 131 & 294 & 392 & 777 & 1043 & 2417 \\
Inv & 1154 & 1237 & 1346 & 1402 & 1624 & 1981 & 2241 & 2355 & 2361 & 2525 & 2525 \\
\hline \multicolumn{7}{l}{ Table 1 presents the annual number of firms that have available data of firm size, B/P, OP and Inv from 2004 to 2014 }
\end{tabular}

Table 1 presents the annual number of firms that have available data of firm size, B/P, OP and Inv from 2004 to 2014 
the bias generated because of the very few firm numbers, the research period of this study is from 2010 to 2014.

The OP for June of year $t$ is calculated as annually revenues minus cost of goods sold, interest expense, and selling, general, and administrative expenses divided by book equity for the last fiscal year end in $t-1$. The investment portfolios are formed on the change in total assets from the fiscal year ending in year $t-2$ to the fiscal year ending in $t-1$, divided by $t-2$ total assets at the end of each June. ${ }^{3}$

The size breakpoint for year $t$ is the median Chinese A-share equity at the end of June of year $t$. The construction of portfolios on OP and investment are similar with that of portfolios on book-to-price ratio. At the end of each June, the firms are sorted into three OP portfolios based on the breakpoints of the 30th and 70th percentiles, and the three investment portfolios are formed in the same way using breakpoints-30th and 70th percentiles.

Similar to FF three factors that are constructed using the 6 value-weighted portfolios formed on size and $\mathrm{B} / \mathrm{M}$ equity $\mathrm{ratio}^{4}$, the FF five factors are constructed on Chinese Ashare stock market using the 6 value-weighted portfolios formed on size and book-toprice (Size-B/P portfolios), the 6 value-weighted portfolios formed on size and operating profitability (Size-OP portfolios), and the 6 value-weighted portfolios formed on size and investment (Size-Inv portfolios). The Size-OP portfolios and Size-Inv portfolios are formed in the same way as the Size-B/M portfolios, except that the second sort variable is operating profitability or investment. At the end of each June, the intersections of two portfolios formed on size, small (S) and big (B), and three portfolios formed on profitability, weak profitability $(\mathrm{W})$, neutral profitability $(\mathrm{N})$, and robust profitability $(\mathrm{R})$, are constructed into six "Size-OP" portfolios: SW, SN, SR, BW, BN, and BR 5 . Similarly, the "SizeInv" portfolios, which are also constructed at the end of each June, are the intersections of two portfolios formed on size and three portfolios formed on investment, conservative investment $(\mathrm{C})$, neutral investment $(\mathrm{N})$, and aggressive investment $(\mathrm{A})$. Thus, the six SizeInv portfolios are constructed: $\mathrm{SC}, \mathrm{SN}, \mathrm{SA}, \mathrm{BC}, \mathrm{BN}$, and $\mathrm{BA}^{6}$.

In FF5F Model, the market factor, which is the excess market return that computed as the difference between the value-weighted returns of all A-shares and the risk-free rate, and value factor remain the same as in the three-factor model, while the size factor SMB need to be reconstructed with profitability and investment factors, which is the average return on the nine small stock portfolios minus the average return on the nine big stock portfolios. The two additional factors are directed at capturing the profitability and investment patterns, which are indicated by RMW and CMA. RMW is the difference between returns on portfolios with robust (SR and BR) and weak profitability (SW and BW), and CMA is the difference between returns on portfolios of the stocks of low (SC and $\mathrm{BC}$ ) and high investment (SA and BA) firms, which is called conservative and aggressive, separately. (More information of constructing FF five factors is presented in Appendix 2.)

Fama and French (2014)) perform the regressions using 25 Size-B/M portfolios, 25 SizeOP portfolios, and 25 Size-Inv portfolios. Following the same method, we firstly construct the three sets of 25 portfolios on Chinese A-share stock market (see Appendix 3). However, there are portfolios which contain no firms or less than five firms. So we choose to sort portfolios into six Size-B/P portfolios, six Size-OP portfolios, and six Size-Inv portfolios; the annual number of firms in the three sets of portfolios is displayed in Table 2. The small size groups of Size-OP portfolios relatively have less stocks than that of big size groups, and the SR portfolio has no stocks in year 2009 and only one stock in SN 
Table 2 Annual number of stocks in three sets of six value-weighted portfolios

\begin{tabular}{|c|c|c|c|c|c|c|}
\hline Year & 2009 & 2010 & 2011 & 2012 & 2013 & 2014 \\
\hline \multicolumn{7}{|c|}{ Panel A: Size-B/P portfolios } \\
\hline SL & 193 & 200 & 227 & 265 & 267 & 254 \\
\hline SM & 280 & 286 & 391 & 446 & 488 & 510 \\
\hline $\mathrm{SH}$ & 192 & 192 & 241 & 301 & 350 & 322 \\
\hline$B L$ & 206 & 206 & 288 & 342 & 395 & 392 \\
\hline BM & 252 & 257 & 296 & 363 & 396 & 360 \\
\hline $\mathrm{BH}$ & 207 & 215 & 275 & 307 & 313 & 324 \\
\hline \multicolumn{7}{|c|}{ Panel B: Size-OP portfolios } \\
\hline SW & 5 & 11 & 22 & 92 & 154 & 488 \\
\hline SN & 1 & 7 & 7 & 52 & 107 & 483 \\
\hline SR & 0 & 5 & 9 & 7 & 13 & 146 \\
\hline BW & 34 & 76 & 95 & 140 & 157 & 233 \\
\hline BN & 51 & 104 & 147 & 210 & 255 & 468 \\
\hline BR & 28 & 57 & 93 & 87 & 121 & 403 \\
\hline \multicolumn{7}{|c|}{ Panel C: Size-Inv portfolios } \\
\hline SC & 328 & 374 & 392 & 404 & 457 & 465 \\
\hline SN & 262 & 288 & 310 & 380 & 412 & 444 \\
\hline SA & 105 & 167 & 289 & 314 & 258 & 244 \\
\hline$B C$ & 187 & 203 & 244 & 277 & 274 & 268 \\
\hline BN & 301 & 373 & 468 & 492 & 496 & 479 \\
\hline BA & 206 & 251 & 276 & 330 & 358 & 409 \\
\hline
\end{tabular}

This table presents the annual firm numbers of six value-weighted Size-B/P portfolios (Panel A), six value-weighted SizeOP portfolios (Panel B), and six Size-Inv portfolios (Panel C) from 2009 to 2014. In the first column of each panel presents correspondingly the six portfolios

portfolio. Therefore, because of the lack of data on firm numbers of Chinese A-share stock market, the interval of our research to processing FF5F Model is from July 2010 to May 2015 (59 months).

\section{Results}

\section{Empirical results on Chinese A-share stock market}

The empirical results of FF5F Model on Chinese A-share stock market during the period July 2010 to May 2015 are reported in this section; furthermore, we also provide the empirical results of FF3F Model over the same time interval for comparison.

Table 3 reports the summary statistics of FF five factors and their correlation coefficients. Panel A is the summary statistics of FF five factors on Chinese stock market, the mean, standard deviation, standard error, sample variance, etc. Panel B is the correlation coefficients among the FF five factors; the profitability and investment factors are both positive related to market factor with low correlation coefficients $(0.0418$ and 0.1190$)$ and negative related to size factor $(-0.2227$ and -0.2199$)$. RMW is negatively related to value factor HML $(-0.0217)$, while CMA is positively and relative highly related to HML with correlation coefficients of 0.4621 . And the correlation coefficient between RMW and CMA is -0.3121 .

Table 4 presents the average excess return of six value-weighted Size-B/P portfolios (Panel A), six value-weighted Size-OP portfolios (Panel B), and six value-weighted Size- 
Table 3 Summary statistics of Fama-French five factors (period: July 2010-May 2015)

\begin{tabular}{llllll}
\hline & RM-RF & SMB & HML & RMW & CMA \\
\hline Panel A: summary statistics of FF five Factors & & & & \\
Mean & -0.0014 & 0.0106 & -0.0059 & -0.0061 & 0.0008 \\
Standard error & 0.0084 & 0.0038 & 0.0046 & 0.0036 & 0.0025 \\
Median & -0.0024 & 0.0117 & -0.0075 & -0.0128 & 0.0001 \\
SD & 0.0646 & 0.0294 & 0.0355 & 0.0273 & 0.0196 \\
Sample variance & 0.0042 & 0.0009 & 0.0013 & 0.0007 & 0.0004 \\
Kurtosis & 0.2068 & 6.4386 & 5.9071 & -0.4204 & -0.2635 \\
Skewness & 0.1439 & -1.2015 & 0.5658 & 0.3288 & 0.2217
\end{tabular}

Panel B: correlation coefficients among FF five factors

RM-RF 1

$\begin{array}{lll}\mathrm{SMB} & 0.1165 & 1\end{array}$

\begin{tabular}{llllll} 
HML & -0.0013 & -0.6970 & 1 & \\
RMW & 0.0418 & -0.2227 & -0.0217 & 1 & \\
CMA & 0.1190 & -0.2199 & 0.4621 & -0.3121 & 1 \\
\hline
\end{tabular}

In this table, Panel A summarizes the mean, standard deviation, and standard error of FF 5 factors, and Panel B is the correlation coefficients among those factors

Inv portfolios (Panel C). It is apparent that there is the size effect: the big size portfolios always have the lower returns than the small size portfolios in each panel. Across the OP groups in Panel B, it is strange that the robust portfolios have lower returns than weak portfolios, perhaps the few data of OP cause the bias. Across the Inv groups in Panel $\mathrm{C}$, it seems the neutral investment portfolios have the highest excess returns ( 0.0158 for small size and neutral investment portfolio, 0.0050 for big size and neutral investment portfolio) than the conservative and aggressive investment portfolios.

The time-series regressions results of the three sets portfolios are demonstrated in Table 5; Panel A, Panel B, and Panel C are the results for the six value-weighted SizeB/P portfolios, Size-OP portfolios and Size-Inv portfolios, separately. All the $t$-statistics reported are corrected for heteroscedasticity and autocorrelation using the NeweyWest estimator with five-lags. The coefficients of excess market return are similar for

Table 4 Average monthly excess returns for portfolios formed on Size-B/M, Size-OP, and Size-Inv

\begin{tabular}{|c|c|c|c|}
\hline \multicolumn{4}{|c|}{ Panel $A$ : excess returns of size-B/P portfolios } \\
\hline & $L$ & M & $\mathrm{H}$ \\
\hline Small & 0.0236 & 0.0231 & 0.0207 \\
\hline Big & 0.0151 & 0.0092 & 0.0061 \\
\hline \multicolumn{4}{|c|}{ Panel B: excess returns of Size-OP portfolios } \\
\hline & W & $\mathrm{N}$ & $\mathrm{R}$ \\
\hline Small & 0.0172 & 0.0170 & 0.0081 \\
\hline Big & 0.0046 & 0.0082 & 0.0016 \\
\hline \multicolumn{4}{|c|}{ Panel C: excess returns of Size-Inv portfolios } \\
\hline & C & N & A \\
\hline Small & 0.0136 & 0.0158 & 0.0121 \\
\hline Big & 0.0033 & 0.0050 & 0.0031 \\
\hline
\end{tabular}

In this table, the average excess returns of six Size-B/M portfolios, Size-OP portfolios, and Size-Inv portfolios are presented in panel $A, B$, and $C$, respectively. Across the columns are the two size groups and across the rows are the three $B / M$ groups, three OP groups, and three Inv groups, respectively 
Table 5 Time-series regressions of three sets of portfolios on FF5F Model, Chinese A-share stock market

\begin{tabular}{|c|c|c|c|c|c|c|}
\hline \multicolumn{7}{|c|}{ Panel A: time-series regressions of six value-weighted Size-B/P portfolios } \\
\hline & \multicolumn{6}{|c|}{ Book-to-price (B/P) ratio } \\
\hline & L & M & $\mathrm{H}$ & L & M & $\mathrm{H}$ \\
\hline & $a$ & & & $t(a)$ & & \\
\hline S & 0.0102 & 0.0105 & 0.0108 & 7.4308 & 4.4938 & 5.6696 \\
\hline \multirow[t]{2}{*}{ B } & 0.0124 & 0.0091 & 0.0118 & 6.8522 & 3.8634 & 6.4458 \\
\hline & $b$ & & & $t(b)$ & & \\
\hline S & 0.9637 & 0.9964 & 0.9703 & 41.1513 & 36.2183 & 35.8284 \\
\hline \multirow[t]{2}{*}{ B } & 0.8361 & 1.0214 & 0.8295 & 27.6969 & 28.5669 & 20.8687 \\
\hline & s & & & $t(s)$ & & \\
\hline$S$ & 1.0039 & 0.9383 & 0.8557 & 15.9153 & 16.3385 & 11.3131 \\
\hline \multirow[t]{2}{*}{ B } & -0.1946 & -0.2434 & -0.0465 & -2.8370 & -2.4971 & -0.5165 \\
\hline & $h$ & & & $t(h)$ & & \\
\hline S & -0.5849 & -0.5197 & -0.2689 & -6.2171 & -6.9004 & -3.9751 \\
\hline \multirow[t]{2}{*}{ B } & -0.9928 & -0.6007 & 0.6912 & -12.4860 & -7.2244 & 5.1532 \\
\hline & $r$ & & & $t(r)$ & & \\
\hline S & -0.0695 & -0.1448 & -0.0617 & -1.1264 & -1.9122 & -0.7331 \\
\hline \multirow[t]{2}{*}{ B } & 0.0188 & -0.0456 & 0.0110 & 0.2597 & -0.6538 & 0.1965 \\
\hline & c & & & $t(c)$ & & \\
\hline S & 0.2515 & 0.1051 & 0.3064 & 2.6156 & 1.0264 & 2.3582 \\
\hline \multirow[t]{2}{*}{ B } & 0.1114 & 0.2802 & 0.0565 & 1.2338 & 3.4851 & 0.5584 \\
\hline & \multicolumn{3}{|c|}{ Adj. R-square } & \multicolumn{3}{|c|}{ Residual standard error } \\
\hline$S$ & 0.9782 & 0.9714 & 0.9606 & 0.0120 & 0.0137 & 0.0148 \\
\hline B & 0.9625 & 0.9609 & 0.9513 & 0.0122 & 0.0136 & 0.0134 \\
\hline
\end{tabular}

Panel B: time-series regressions of six Size-OP portfolios Operating Profitability

$\begin{array}{llllll}W & N & R & W & N & R \\ a & & & t(a) & & \\ 0.0012 & 0.0020 & -0.0018 & 0.5498 & 0.4592 & -1.0778 \\ -0.0009 & 0.0028 & 0.0021 & -0.5008 & 1.4503 & 0.6190 \\ b & & t(b) & & \\ 1.0075 & 1.0408 & 1.0492 & 35.8879 & 20.1490 & 31.7018 \\ 1.1300 & 1.0253 & 1.0883 & 26.7879 & 34.3991 & 25.3012 \\ s & & & t(s) & & \\ 1.1712 & 0.9800 & 1.5637 & 13.2828 & 5.5382 & 18.1679 \\ 0.2480 & 0.2628 & -0.1445 & 2.3517 & 3.3480 & -1.1030 \\ h & & & t(h) & & \\ -0.4482 & -0.7244 & -0.2020 & -4.5108 & -3.9157 & -1.9726 \\ -0.4560 & -0.5496 & -0.7022 & -4.4978 & -5.9760 & -6.6825 \\ r & & & t(r) & & \\ -0.3429 & -0.2601 & 1.1319 & -4.6763 & -2.5519 & 15.7233 \\ -0.2265 & -0.1198 & 0.2987 & -3.5011 & -1.3591 & 3.4009 \\ c & & & t(c) & & \\ 0.2644 & 0.1610 & 0.5398 & 2.4244 & 0.7310 & 4.2483\end{array}$


Table 5 Time-series regressions of three sets of portfolios on FF5F Model, Chinese A-share stock market (Continued)

\begin{tabular}{|c|c|c|c|c|c|c|}
\hline \multirow[t]{2}{*}{ B } & 0.4613 & 0.0414 & 0.1860 & 5.8956 & 0.3561 & 1.3955 \\
\hline & \multicolumn{3}{|c|}{ Adj. R-square } & \multicolumn{3}{|c|}{ Residual standard error } \\
\hline S & 0.9720 & 0.9301 & 0.9653 & 0.0143 & 0.0238 & 0.0172 \\
\hline B & 0.9643 & 0.9640 & 0.9486 & 0.0150 & 0.0139 & 0.0172 \\
\hline \multicolumn{7}{|c|}{ Panel C: time-series regressions of six Size-Inv portfolios } \\
\hline & \multicolumn{6}{|c|}{ Investment } \\
\hline & C & $\mathrm{N}$ & A & C & $\mathrm{N}$ & A \\
\hline & $a$ & & & $t(\mathrm{a})$ & & \\
\hline S & -0.0017 & 0.0018 & -0.0016 & -1.0068 & 0.8186 & -0.9026 \\
\hline \multirow[t]{2}{*}{ B } & -0.0029 & 0.0003 & -0.0030 & -1.5573 & 0.1566 & -1.5819 \\
\hline & \multicolumn{3}{|l|}{$b$} & \multicolumn{3}{|l|}{$t(b)$} \\
\hline S & 1.0274 & 1.0548 & 1.0708 & 35.4151 & 33.9728 & 31.3516 \\
\hline \multirow[t]{2}{*}{ B } & 1.1116 & 1.0704 & 1.0683 & 27.7982 & 32.5243 & 27.9726 \\
\hline & \multicolumn{3}{|l|}{$s$} & \multicolumn{3}{|l|}{$t(s)$} \\
\hline S & 1.1998 & 1.1137 & 1.2837 & 14.5888 & 14.7519 & 18.0777 \\
\hline \multirow[t]{2}{*}{ B } & 0.4978 & 0.3165 & 0.4139 & 5.5174 & 4.7070 & 4.0713 \\
\hline & \multicolumn{3}{|l|}{$h$} & \multicolumn{3}{|l|}{$t(h)$} \\
\hline S & -0.5135 & -0.5369 & -0.2393 & -4.8437 & -6.2005 & -2.2282 \\
\hline \multirow[t]{2}{*}{ B } & -0.3527 & -0.4482 & -0.6269 & -3.2055 & -5.6888 & -5.9485 \\
\hline & \multicolumn{3}{|l|}{$r$} & \multicolumn{3}{|l|}{$t(r)$} \\
\hline S & -0.0871 & -0.0789 & -0.1329 & -0.9804 & -0.8737 & -1.3784 \\
\hline \multirow[t]{2}{*}{ B } & 0.0023 & -0.0330 & 0.0481 & 0.0249 & -0.5768 & 0.5404 \\
\hline & \multicolumn{3}{|l|}{$c$} & \multicolumn{3}{|l|}{$t(c)$} \\
\hline S & 0.5330 & -0.0210 & -0.7507 & 3.2129 & -0.2007 & -4.8137 \\
\hline \multirow[t]{2}{*}{ B } & 0.4623 & 0.0445 & -0.2540 & 3.7475 & 0.4260 & -1.9740 \\
\hline & \multicolumn{3}{|c|}{ Adj. R-square } & \multicolumn{3}{|c|}{ Residual standard error } \\
\hline S & 0.9739 & 0.9713 & 0.9722 & 0.0141 & 0.0149 & 0.0148 \\
\hline B & 0.9595 & 0.9680 & 0.9607 & 0.0160 & 0.0135 & 0.0157 \\
\hline
\end{tabular}

Regression: $R_{i, t}-R_{f}=a_{i}+b_{i}\left(R_{M, t}-R_{f}\right)+s_{i} \mathrm{SMB}+h_{i} \mathrm{HML}+r_{i} \mathrm{RMW}+c_{i} \mathrm{CMA}+e_{i, t}$

This table presents the time-series regressions results of six value-weighted Size-B/P portfolios, six value-weighted Size-OP portfolios, and six value-weighted Size-Inv portfolios on FF5F Model on Chinese A-share stock market during the period July 2010 to May 2015 (59 months). In each panel, the regression intercept $a$, the regression coefficients $b, s, h, r$, and $c$ of market factor, size factor, value factor, profitability factor, and investment factor and adjusted R-square are respectively presented in the left part of the table; the corresponding $t$-statistics corrected for heteroscedasticity and autocorrelation using the NeweyWest estimator with five-lags and residual standard error are presented in the right part. Panel $A$ is the regressions on six value-weighted Size-B/P portfolios; across the columns are the two size groups (small and big), and across the rows are the three B/P groups (low, medium, and high). Panel B is the regression results of six Size-OP portfolios, same as Panel A; across the columns are the two size groups, and across the rows are the three OP groups (weak, neutral, and robust). Panel C is the regression results of six Size-Inv portfolios; across the columns are the two size groups, and across the rows are the three investment groups (conservative, neutral, and aggressive). Numbers in italics are the $t$-stats which are significant at $5 \%$ confidence level

all the three sets of portfolios; the coefficients of market factor are always around 1 and highly significant at $5 \%$ confidence level.

In Panel A, the intercepts are significantly distinguishable from zero, which means that FF5F Model may not completely capture the expected returns of Size-B/P portfolios. The regression coefficients of size factor SMB are all significant at $5 \%$ confidence level except the portfolio of big size and high $\mathrm{B} / \mathrm{P}$ ratio, and the sign of slopes indicate that portfolios of small size have returns that are positively related to size factor, while returns of big size 
portfolios are negatively related to size factor. The increase slopes of HML $(h)$ across the size groups state that return of portfolios are positively related to B/P ratio. However, only one of the coefficients of profitability factor is marginally significant, and three out of six coefficients of investment factor are significant at $5 \%$ confidence level.

In Panel B, the regression results for market factor, size factor, and value factor are fairly the same; the big difference is in profitability factor RMW; all coefficients are significant $\mathrm{BN}$, and across size groups, more profitability portfolios tend to have higher excess returns. Three out of six coefficients of investment factor CMA are significant, two are the weak portfolios ( 0.2644 for portfolio SW with $t$-stats 2.4244 and 0.4613 for portfolio BW with $t$-stats 5.8956) and one is the portfolio SR (coefficients 0.5398 with $t$-stats 4.2483). In Panel C, the regression results of market factor, SMB factor, and HML factor are all satisfactory significant. The results for RMW is like Panel A, none of which is significant. And for the CMA factor, the result is similar as six Size-OP portfolios in Panel B, three coefficients of portfolio SC, BC, and SA are significant. And the investment effect is alike in the results of 25 Size-Inv portfolios in (Fama and French, 2014), in which the aggressive investment portfolios have lower excess returns.

To summarize, market beta always plays an important role in explaining time-series variation of excess portfolio returns. For all the three sets of portfolios, there exists size effect that the excess returns are negatively related to firm size. And the value effect exists only in Size-B/P portfolios not in Size-OP and Size-Inv portfolios. For RMW, the coefficients are only significant in the Size-OP portfolios, but not in two other groups of portfolios. As to the CMA factor, the portfolios which have the weak profitability in Size-OP portfolios and portfolios which have the conservative investment in Size-Inv portfolios have positive coefficients; in addition, there is positive coefficient for the small size-robust OP portfolio and negative coefficient for the small size-aggressive investment portfolio. However, for the Size$\mathrm{B} / \mathrm{M}$ portfolios, the CMA significant coefficients are relatively dispersive. FF5F Model explains the Size-OP portfolios better than the other two sets of portfolios.

In order to investigate whether profitability and investment factors have additional explanatory power beyond FF3F Model and compare the performance of both FF3F Model and FF5F Model on Chinese A-share stock market during our research period, we implement the time-series regressions of the same three sets of portfolios (six value-weighted Size-B/P portfolios, six value-weighted Size-OP portfolios, and six value-weighted Size-Inv portfolios) on FF3F model over the same time interval (July 2010-May 2015). The regressions results are presented in Table 6.

In Panel A of Table 6 (five out of six), loadings on SMB and HML are highly significant at $5 \%$ confidence level, and there exists stable size and value effect. In comparison with the results of FF5F Model (Panel A of Table 5), the explanatory power of size and value factor are much alike with or without the presence of profitability and investment factors. Though three out of six loadings on CMA are statistically significant, comparing the adjusted R-squares, FF5F Model seems not to perform better than FF3F Model during the research period. Thus, profitability and investment factors do not increase the explanatory power of FF three factors when regressions are implemented for six value-weighted Size-B/P portfolios.

Comparing Panel B of Tables 5 and 6, the presence of RMW and CMA factors captures more time-series variation of average excess portfolio returns; FF5F Model explains average excess returns of six Size-OP portfolios better than FF3F Model regarding to the adjusted R-squares. Though four out of six loadings on CMA are significant in Panel C of 
Table 6 Time-series regression of three sets of portfolios on FF3F Model, Chinese A-share stock market

\begin{tabular}{|c|c|c|c|c|c|c|}
\hline \multicolumn{7}{|c|}{ Panel A: time-series regression of six value-weighted Size-B/P portfolios } \\
\hline & \multicolumn{6}{|c|}{ Book-to-price (B/P) ratio } \\
\hline & $\mathrm{L}$ & M & $\mathrm{H}$ & L & M & $\mathrm{H}$ \\
\hline & a & & & $t(a)$ & & \\
\hline S & 0.0113 & 0.0113 & 0.0112 & 7.4842 & 4.5837 & 6.1412 \\
\hline \multirow[t]{2}{*}{ B } & 0.0123 & 0.0092 & 0.0123 & 6.2322 & 3.3146 & 6.4849 \\
\hline & $b$ & & & $t(b)$ & & \\
\hline S & 0.8979 & 0.9231 & 0.9059 & 32.6701 & 27.0157 & 32.2014 \\
\hline \multirow[t]{2}{*}{ B } & 0.8504 & 1.0340 & 0.8424 & 27.3918 & 22.4104 & 22.1472 \\
\hline & $s$ & & & $t(s)$ & & \\
\hline S & 0.9057 & 0.8874 & 0.8548 & 27.9738 & 15.5660 & 19.8422 \\
\hline \multirow[t]{2}{*}{$B$} & -0.1441 & -0.1149 & -0.0931 & -3.4693 & -1.3686 & -2.7201 \\
\hline & $h$ & & & $t(h)$ & & \\
\hline S & -0.4025 & -0.3497 & -0.0262 & -5.0751 & -4.3756 & -0.4383 \\
\hline \multirow[t]{2}{*}{ B } & -0.9630 & -0.4761 & 0.6607 & -15.1937 & -5.5671 & 7.1594 \\
\hline & \multicolumn{3}{|c|}{ Adj. R-square } & \multicolumn{3}{|c|}{ Residual standard error } \\
\hline & 0.9803 & 0.9782 & 0.9746 & 0.0114 & 0.0120 & 0.0119 \\
\hline 3 & 0.9623 & 0.9545 & 0.9542 & 0.0122 & 0.0147 & 0.0130 \\
\hline
\end{tabular}

Panel B: time-series regression of six value-weighted Size-OP portfolios Profitability

$\begin{array}{llllll}\text { W } & \mathrm{N} & \mathrm{R} & \mathrm{W} & \mathrm{N} & \mathrm{R}\end{array}$

a t(a)

$\begin{array}{lllllll}\text { S } & 0.0038 & 0.0042 & -0.0022 & 1.3466 & 0.7791 & -0.5303 \\ \text { B } & 0.0000 & 0.0027 & 0.0010 & -0.0179 & 1.5449 & 0.3059 \\ & b & & & t(b) & \\ \text { S } & 0.9236 & 0.9733 & 1.0657 & 24.3001 & 17.2826 & 17.4507 \\ \text { B } & 1.0967 & 0.9896 & 1.1164 & 19.0453 & 34.3179 & 20.3752 \\ & \text { S } & & & t(s) & & \\ \text { S } & 1.0674 & 0.8611 & 0.7540 & 7.9772 & 5.1362 & 5.5995 \\ \text { B } & 0.4230 & 0.3508 & -0.1688 & 3.8493 & 7.9956 & -1.5525 \\ & \text { h } & & & t(h) & & \\ \text { S } & -0.2302 & -0.5825 & -0.4059 & -1.8362 & -3.4193 & -2.2086 \\ \text { B } & -0.1523 & -0.4188 & -0.7060 & -1.3302 & -4.9840 & -6.5449 \\ & \text { Adj. R-square } & & & \text { Residual standard error } & \\ \text { S } & 0.9456 & 0.9158 & 0.8514 & 0.0200 & 0.0261 & 0.0356 \\ \text { B } & 0.9520 & 0.9698 & 0.9388 & 0.0174 & 0.0127 & 0.0188\end{array}$

Panel C: time-series regressions of six value-weighted Size-Inv portfolios Investment

\begin{tabular}{|c|c|c|c|c|c|c|}
\hline & C & N & A & $C$ & $\mathrm{~N}$ & A \\
\hline & $a$ & & & $t(a)$ & & \\
\hline S & -0.0002 & 0.0024 & -0.0015 & -0.1061 & 1.1784 & -0.7269 \\
\hline B & -0.0025 & 0.0000 & -0.0038 & -1.3087 & 0.0310 & -2.4503 \\
\hline & $b$ & & & $t(b)$ & & \\
\hline S & 0.9521 & 0.9745 & 0.9667 & 34.0437 & 37.7947 & 50.2415 \\
\hline
\end{tabular}


Table 6 Time-series regression of three sets of portfolios on FF3F Model, Chinese A-share stock market (Continued)

\begin{tabular}{lllllll}
\hline B & 1.0796 & 1.0393 & 1.0323 & 26.3027 & 37.0603 & 31.6716 \\
& $S$ & & & $t(s)$ & \\
S & 1.1180 & 0.9787 & 1.0170 & 19.8524 & 22.2040 & 16.8657 \\
B & 0.5370 & 0.3491 & 0.3535 & 8.8230 & 7.1627 & 5.0630 \\
& $h$ & & $t(h)$ & & \\
S & -0.2089 & -0.4312 & -0.3873 & -2.3319 & -5.7192 & -3.2013 \\
B & -0.1090 & -0.3505 & -0.6595 & -0.9868 & -4.6239 & -7.1360 \\
& Adj. R-square & & & Residual standard error & \\
S & 0.9701 & 0.9778 & 0.9508 & 0.0151 & 0.0131 & 0.0197 \\
B & 0.9595 & 0.9742 & 0.9621 & 0.0160 & 0.0121 & 0.0155 \\
\hline
\end{tabular}

Regression: $R_{i, t}-R_{f}=a_{i}+b_{i}\left(R_{M, t}-R_{f}\right)+s_{i} S M B+h_{i} H M L+\varepsilon_{i, t}$

This table reports the time-series regression of six value-weighted Size-B/P portfolios, six value-weighted Size-OP portfolios, and six value-weighted Size-Inv portfolios on FF3F Model on Chinese A-share stock market; across the columns are the two size groups, and across the rows are the three B/P ratio groups. The left part of the table is the coefficients obtained from the regressions ( $a$ is the intercept, $b, s$, and $h$ are the regression slopes of FF three factors separately) and adjusted R-square. Correspondingly, the right part of the table is $t$-statistics corrected for heteroscedasticity and autocorrelation using the Newey-West estimator and the standard error of the estimation $\varepsilon_{i, t}$. Numbers in italics are the $t$-statistics which are significant at $5 \%$ confidence level

Table 5, the values of adjusted R-squares are very close for FF3F Model and FF5F Model. We cannot tell the big difference between the ability of two models in capturing the timeseries variation of returns of six value-weighted Size-Inv portfolios.

In general, comparing the empirical results of FF3F Model, especially for the adjusted R-square term, the FF5FModel does not improve a lot and only slightly better in explaining the six value-weighted Size-OP portfolios.

\section{Fama-French Five-Factor Model on US stock market}

We implement the same time-series regressions on FF5F Model as reported in Table 5 using data of US market. The three sets of portfolios are downloaded directly from Kenneth R. French's website, and the time-series regression results are reported in Table 7. The slopes of excess market return are always close to 1 and strongly positive for all three sets of portfolios of both countries. The slopes of SMB are strongly positive for small stocks and slightly positive or negative for big stocks; there exists size effect on both stock markets.

We next compare between each panels of Table 5 (Chinese market) and Table 7 (US market). Comparing "Panel A" of both tables, there exists value effect on both stock markets. As to the profitability factor RMW, four out of six loadings on RMW are statistically significant and specially all three loadings on small portfolios are negatively significant in the USA, while none of the loadings on RMW is significant at $5 \%$ confidence level in China. The slopes on RMW and CMA show not clear relationship between portfolio returns and profitability or investment.

Comparing Panel B, the regression results of six Size-OP portfolios are approximately close. All the slopes on profitability factor RMW are strongly significant, among which the slopes are strongly negative for the weak OP portfolios (low profitability) and strongly positive for the robust OP portfolios (high profitability) on US stock market, while five out of six loadings on RMW are significant on Chinese A-share stock market with the same pattern as US market. It is noticed that the loadings on CMA factor are 
Table 7 Time-series regressions of three sets of portfolios on FF5F Model on US stock market Panel A: time-series regressions on six Size-B/M portfolios Book-to-Market (B/M) ratio

\begin{tabular}{|c|c|c|c|c|c|c|}
\hline & L & M & $\mathrm{H}$ & L & M & $\mathrm{H}$ \\
\hline & & $a$ & & & $t(a)$ & \\
\hline S & -0.2123 & -0.0328 & 0.2391 & -1.2440 & -0.3040 & 1.4394 \\
\hline B & 0.0339 & -0.0369 & 0.0197 & 0.2766 & -0.2794 & 0.1673 \\
\hline & & $b$ & & & & \\
\hline$S$ & 0.9867 & 1.0036 & 0.8091 & 18.0426 & 37.3893 & 18.0305 \\
\hline B & 1.0715 & 1.1142 & 1.0577 & 30.4708 & 21.6453 & 42.6438 \\
\hline & & s & & & & \\
\hline S & 0.7036 & 0.7975 & 0.4312 & 13.4733 & 17.5148 & 5.5548 \\
\hline B & 0.2231 & 0.1980 & 0.1550 & 4.6577 & 3.4748 & 2.2473 \\
\hline & & $h$ & & & & \\
\hline S & -0.2137 & 0.2549 & 0.3912 & -2.0573 & 4.1878 & 3.8325 \\
\hline B & -0.2152 & 0.0582 & 0.6456 & -4.9748 & 0.9063 & 9.2306 \\
\hline & & $r$ & & & & \\
\hline S & -0.7327 & -0.1351 & -0.3846 & -5.4871 & -2.2599 & -3.0270 \\
\hline B & -0.1506 & -0.0322 & 0.0110 & -2.7377 & -0.3318 & 0.1531 \\
\hline & & c & & & & \\
\hline S & -0.3047 & -0.2155 & -0.0974 & -2.7655 & -2.3334 & -0.7657 \\
\hline & -0.2294 & -0.0887 & -0.1666 & -2.3567 & -1.1923 & -1.4554 \\
\hline
\end{tabular}

Adj. R-square

Residual standard error

$\begin{array}{lllllll}\text { S } & 0.9517 & 0.9733 & 0.9084 & 1.152 & 0.7979 & 1.251 \\ B & 0.967 & 0.9591 & 0.958 & 0.7727 & 0.8809 & 0.8895\end{array}$

Panel B: time-series regressions on Size-OP portfolios

Operating profitability

W N

S $\quad-0.0188$

$-0.0842$

B

$S$

B

S $\quad-0.1143$

B $\quad 0.2443$

S $\quad-0.6348$

B $\quad-0.5864$

S $\quad 0.0768$

B $\quad-0.2849$
N

0.0898

0.0989

b

$s$

0.9675

$-0.0541$

h

0.2669

0.0392

$r$

0.2597

$-0.1016$

$c$

$-0.0627$

0.1389
R

$-0.0396$

$-0.0640$

1.0646

1.0298

W

$-0.3438$

$-0.7461$

81.0285

27.2225

0.9317

$-0.1339$

0.2011

$-0.0708$

0.4475

0.3304

$-0.1247$

$-0.0839$

33.4687

$-1.0857$

$-4.5007$

4.5818

$-8.4796$

1.6662

$-3.0221$
N

t(a)

1.1708

2.2880

51.1117

50.5000

20.9395

$-1.2950$

6.3486

1.0984

5.1374

$-2.7847$

$-1.0611$

2.6995

$-1.5351$

$-2.0856$ 
Table 7 Time-series regressions of three sets of portfolios on FF5F Model on US stock market (Continued)

\begin{tabular}{|c|c|c|c|c|c|c|}
\hline \multirow[b]{2}{*}{ S } & \multicolumn{3}{|c|}{ Adj. R-square } & \multicolumn{3}{|c|}{ Residual standard error } \\
\hline & 0.9945 & 0.9851 & 0.9826 & 0.3928 & 0.5772 & 0.629 \\
\hline B & 0.9775 & 0.9863 & 0.9903 & 0.6871 & 0.4101 & 0.3345 \\
\hline \multicolumn{7}{|c|}{ Panel C: time-series regressions on Size-Inv portfolios } \\
\hline & \multicolumn{6}{|c|}{ Investment } \\
\hline & \multirow[t]{2}{*}{ C } & N & \multirow[t]{2}{*}{ A } & \multirow[t]{2}{*}{ C } & $\mathrm{N}$ & \multirow[t]{2}{*}{ A } \\
\hline & & $a$ & & & $t(a)$ & \\
\hline$S$ & -0.0540 & 0.1144 & 0.0071 & -0.8730 & 2.3620 & 0.1573 \\
\hline \multirow[t]{2}{*}{ B } & \multirow[t]{2}{*}{0.0831} & -0.0428 & \multirow[t]{2}{*}{0.0259} & \multirow[t]{2}{*}{1.1236} & -0.7299 & \multirow[t]{2}{*}{0.4733} \\
\hline & & $b$ & & & & \\
\hline S & 1.0880 & 0.9710 & 0.9681 & 81.6853 & 35.9423 & 47.1125 \\
\hline \multirow[t]{2}{*}{ B } & \multirow[t]{2}{*}{0.9326} & 0.9912 & \multirow[t]{2}{*}{1.0521} & \multirow[t]{2}{*}{32.4959} & 48.6599 & \multirow[t]{2}{*}{77.8118} \\
\hline & & s & & & & \\
\hline S & 0.8760 & 0.8942 & 0.9702 & 19.7427 & 26.8312 & 30.5318 \\
\hline \multirow[t]{2}{*}{ B } & \multirow[t]{2}{*}{-0.0835} & -0.0167 & \multirow[t]{2}{*}{-0.1786} & \multirow[t]{2}{*}{-2.1632} & -0.9118 & \multirow[t]{2}{*}{-5.7904} \\
\hline & & $h$ & & & & \\
\hline S & -0.0163 & 0.1754 & 0.0238 & -0.3663 & 5.4018 & 0.7234 \\
\hline \multirow[t]{2}{*}{ B } & \multirow[t]{2}{*}{-0.0260} & 0.0615 & \multirow[t]{2}{*}{-0.0658} & \multirow[t]{2}{*}{-0.4450} & 1.3401 & \multirow[t]{2}{*}{-1.4661} \\
\hline & & $r$ & & & & \\
\hline S & -0.2339 & 0.1339 & -0.2181 & -5.6108 & 3.5684 & -4.7274 \\
\hline \multirow[t]{2}{*}{ B } & \multirow[t]{2}{*}{-0.0001} & 0.0573 & \multirow[t]{2}{*}{-0.0174} & -0.0013 & 1.1884 & -0.3659 \\
\hline & & c & & & & \\
\hline S & 0.3567 & 0.1159 & -0.4264 & 5.2777 & 2.0770 & -7.7210 \\
\hline B & 0.6429 & 0.1819 & -0.5734 & 7.3145 & 3.4479 & -8.1165 \\
\hline & Adj. R-sq & & & Residual & error & \\
\hline S & 0.9908 & 0.9879 & 0.9907 & 0.5122 & 0.5121 & 0.4829 \\
\hline B & 0.9764 & 0.9872 & 0.9799 & 0.5425 & 0.4094 & 0.5188 \\
\hline
\end{tabular}

Regression: $R_{i, t}-R_{f}=a_{i}+b_{i}\left(R_{M, t}-R_{f}\right)+s_{i} \mathrm{SMB}+h_{i} \mathrm{HML}+r_{i} \mathrm{RMW}+c_{i} \mathrm{CMA}+e_{i, t}$

This table presents the time-series regression results of six value-weighted Size-B/P portfolios, six value-weighted Size-OP portfolios, and six value-weighted Size-Inv portfolios on FF5F Model on US stock market. In each panel, the regression intercept $a$, the regression coefficients $b, s, h, r$, and $c$ of market factor, size factor, value factor, profitability factor and investment factor, and adjusted $\mathrm{R}$ square are respectively presented in the left part of the table; the corresponding $t$-statistics corrected for heteroscedasticity and autocorrelation using the Newey-West estimator and residual standard error are presented in the right part. Panel $A$ is the regressions on six Size-B/M portfolios; across the columns are the two size groups (small and big), and across the rows are the three B/M groups (low, medium, and high). Panel B is the regression results of six Size-OP portfolios, same as Panel A; across the columns are the two size groups, and across the rows are the three OP groups (weak, neutral, and robust). Panel C is the regression results of six Size-Inv portfolios; across the columns are the two size groups, and across the rows are the three investment groups (conservative, neutral, and aggressive). Numbers in italics are the $t$-stats which are significant at $5 \%$ confidence level

significant only for the three big size portfolios in US, and the slopes are not related to portfolios profitability. We find no apparent value effect when regressing the six SizeOP portfolios on FF5F Model on both stock markets.

The regression results for the six Size-Inv portfolios are quite different comparing Panel $\mathrm{C}$ of both markets. First, most loadings on HML lose their significance (only one out of six is significant) in the USA, while all the portfolios have strong negative exposure to HML on Chinese stock market but no value effect. Then, the small size portfolios always have significant exposure to RMW in the USA; while none of the loadings on RMW is significant on Chinese A-share stock market for the Size-Inv portfolios. 
Last, CMA factor seems to explain more time-series variation of excess stock returns in the USA than in China, since all the loadings on CMA are significant while only loadings of conservative and aggressive portfolios are significant on Chinese stock market. The slopes of conservative (low investment) portfolios are positive and the slopes of aggressive (high investment) portfolios are negative on both markets, which is consistent with FF's expected pattern.

Furthermore, the adjusted R-squares of six Size-OP portfolios and six Size-Inv portfolios are slightly bigger in the USA than that in China, which indicates that FF5F Model explains the two sets of portfolios slightly better on US stock market than on Chinese A-share stock market. In addition, the profitability factor and investment factor are able to capture partially time-series variation of all three sets of portfolios' returns on US stock market, while on Chinese stock market, the profitability factor seems to be an explanatory factor only for the six Size-OP portfolios, where the portfolios are sorted by OP.

\section{Discussion}

Though less explanatory power than on US stock market, FF3F Model is able to capture more than $90 \%$ of time-series variation of average excess stock returns on Chinese A-share stock market during the research period. However, it remains less than $10 \%$ of average returns that cannot explained by FF3F Model. This study investigates two augmented factors proposed by FF recently, profitability factor and investment factor, but we find no significant improvement of FF5F Model comparing to FF3F Model except for the six value-weighted Size-OP portfolios.

Since there exist several special features on Chinese stock market, the determinants for asset returns might be different from those in developed countries such as the USA. One possible extension of this study is to consider alternative factors instead of profitability and investment factors, such as factors related to macroeconomic variables (GDP growth, money supply, and interest rate) and industry factors (such as industrial production), or particularly country factors considering Chinese special characteristics (such as policy of Chinese government), which is beyond the scope of this study but is our research in process.

\section{Conclusions}

To investigate the explanatory power of profitability and investment factors, we apply FF5F Model on Chinese A-share stock market during the period July 2010 to May 2015 and construct three sets of portfolios, six value-weighted Size-B/P portfolios, six valueweighted Size-OP portfolios, and six value-weighted Size-Inv portfolios. For all the three sets of portfolios, market factor, size factor, and value factor have strong explanatory power for the expected excess returns in the presence of profitability and investment factors. There always exists size effect that the excess returns are negatively related to firm size, and the value effect exists only in Size-B/P portfolios. The CMA factor do have explanatory power for certain portfolios in all three sets of portfolios. However, the RMW factor seems not so convincible; profitability effect exists only in six Size-OP portfolios, in which excess returns are positively related to firms' profitability.

In comparison with FF3F Model, in the presence of profitability factor RMW and investment factor CMA, the value factor HML has been well explained in all three sets of portfolios. However, augmenting FF3F Model with profitability and investment factors 
seems not to capture more time-series variation of average excess stock returns than FF3F Model alone except for the six value-weighted Size-OP portfolios. Overall, we cannot conclude that FF5F Model performs better than FF3F on Chinese A-share stock market during the research period July 2010 to May 2015.

We also implement the regressions over the same period using US data. The empirical results reveal that FF5F Model explain time-series variation of average excess stock returns slightly better in US stock market than in Chinese A-share stock market. As for the two new factors, profitability factor and investment factor are able to capture partially time-series variation of all three sets of portfolios' returns on US stock market, while on Chinese stock market, the profitability factor seems to be an explanatory factor only for the six Size-OP portfolios. Thus, we propose to augment FF3F Model with factors considering special features of Chinese stock market for future research.

\section{Endnotes}

${ }^{1}$ Recently, Novy-Marx (2013) identifies a proxy today that predicts expected earnings tomorrow; the profitability factor, which is strongly related to average stock return, and the investment factor were documented by Aharoni, Grundy, and Zeng (2013); see also Titman, Wei and Xie (2004). Although it has a high correlation with the value and profitability factors, the investment effect is perhaps half as strong, but it is still reliable and significant.

${ }^{2}$ The three sets of factors are $2 \times 3$ sorts on Size and B/M, or Size and OP, or Size and Inv; $2 \times 2$ sorts on Size and B/M, or Size and OP, or Size and Inv; and $2 \times 2 \times 2 \times 2$ sorts on Size, B/M, OP, and Inv (see details in Fama and French, 2014). In $2 \times 3$ sorts on Size and $\mathrm{B} / \mathrm{M}$, the size and value factors independently sort stocks into two size groups and three $\mathrm{B} / \mathrm{M}$ groups and construct the size factor $\mathrm{SMB}$ and value factor HML as of FF3F model; the $2 \times 3$ sorts on Size and OP or Size and Inv are the same as Size and B/M except the sort for $\mathrm{B} / \mathrm{M}$ groups is replaced by operating profitability or investment. $2 \times 2$ sorts' method is similar as $2 \times 3$ sorts except that the stocks are all independently sorted into two groups. In $2 \times 2 \times 2 \times 2$ sorts, the size factor SMB equals the weights high and low $\mathrm{B} / \mathrm{M}$, robust and weak $\mathrm{OP}$, and conservative and aggressive Inv portfolio returns.

${ }^{3}$ Details are available on Kenneth R. French's website.

${ }^{4}$ In June of each year $t$, the stocks are sorted into two size groups: small firms (S) and big firms (B), according to their total market value. Independently, stocks are sorted into three $\mathrm{B} / \mathrm{P}$ groups instead of $\mathrm{B} / \mathrm{M}$ ratio at each December of year $t-1$ : low $\mathrm{B} / \mathrm{P}$ ratio $(\mathrm{L})$, medium $\mathrm{B} / \mathrm{P}$ ratio $(\mathrm{M})$, and high $\mathrm{B} / \mathrm{P}$ ratio $(\mathrm{H})$ firms, according to the breakpoint 30 and $70 \%$ of values of $\mathrm{B} / \mathrm{P}$ equity for all the stocks. The intersections of these groups are constructed into six portfolios: small low (SL), small medium (SM), small high (SH), big low $(\mathrm{BL})$, big medium (BM), and big high (BH) portfolios. The value-weighted monthly returns are calculated from July of year $t$ to June of year $t+1$, during which the portfolios remain the same, and the portfolios are reconstructed in July of year $t+1$.

${ }^{5}$ Portfolio SW contains firms with small size and weak profitability; SN contains firms with small size and neutral profitability; SR contains firms with small size and robust profitability, similarly to BW, BN, and BR, which contain firms with big size and weak profitability, neutral profitability, and robust profitability separately.

${ }^{6}$ Portfolio SC contains firms with small size and conservative investment; SN contains firms with small size and neutral investment; SA contains firms with small size and aggressive investment, similarly to $\mathrm{BC}, \mathrm{BN}$ and $\mathrm{BA}$ portfolios. 


\section{Appendix 1}

In their paper, Fama and French suggest that the theoretical starting point is the "Dividend Discount Model":

$$
m_{t}=\sum_{\tau=1}^{\infty} E\left(d_{t+\tau}\right) /(1+r)^{\tau}
$$

Where $m_{t}$ is the share price at time $t, E\left(d_{t+\tau}\right)$ is the expected dividend per share for period $t+\tau$, and $r$ is (approximately) the long-term average expected stock return or, more precisely, the internal rate of return on expected dividends. This model states that the value of a stock today will be the sum of the discounted present value of all its future dividends.

With a little bit manipulation, the dividend per share $d_{t+\tau}$ is the difference between $Y_{t+\tau}$, the equity earnings for period $\mathrm{t}+\mathrm{\tau}$, and $d B_{t+\tau}=B_{t+\tau}-B_{t+\tau-1}$, which is the change in book equity. Then, the dividend discount model (Eq. 3) becomes:

$$
M_{t}=\sum_{\tau=1}^{\infty} E\left(Y_{t+\tau}-d B_{t+\tau}\right) /(1+r)^{\tau}
$$

Divided by book equity at time $t$ gives

$$
\frac{M_{t}}{B_{t}}=\frac{\sum_{\tau=1}^{\infty} E\left(Y_{t+\tau}-d B_{t+\tau}\right) /(1+r)^{\tau}}{B_{t}}
$$

Equation (4) implies three statements about expected stock returns.

- Firstly, fix everything except the expected stock return $r$ and current value of the stock $M_{t}$, a lower market value $M_{t}$, or equivalent to a higher book-to-market equity $(\mathrm{B} / \mathrm{M})$ ratio implies a higher expected stock return.

- Next, fix everything except the expected earnings $Y_{t+\tau}$ and expected stock returns $r$, more profitable companies which with higher expected earnings have higher expected returns.

- Finally, controlling for the expected growth $d B_{t+\tau}$ (investment) and expected stock returns while fixing other elements, firms with higher expected growth in book equity implies a lower expected return.

\section{Appendix 2}

$$
\begin{aligned}
\mathrm{HML}= & \frac{1}{2}(\text { Small High }+ \text { Big High })-\frac{1}{2}(\text { Small Low }+ \text { Big Low }) \\
\mathrm{SMB}_{B / M}= & \frac{1}{3}(\text { Small Low }+ \text { Small Medium }+ \text { Small High }) \\
& -\frac{1}{3}(\text { Big Low }+ \text { Big Medium }+ \text { Big High }) \\
\mathrm{SMB}_{\mathrm{OP}}= & \frac{1}{3}(\text { Small Robust }+ \text { Small Neutral }+ \text { Small Weak }) \\
& -\frac{1}{3}(\text { Big Robust }+ \text { Big Neutral }+ \text { Big Weak }) \\
\mathrm{SMB}_{\text {Inv }}= & \frac{1}{3}(\text { Small Conservative }+ \text { Small Neutral }+ \text { Small Aggressive }) \\
& -\frac{1}{3}(\text { Big Conservative }+ \text { Big Neutral }+ \text { Big Aggressive })
\end{aligned}
$$




$$
\begin{aligned}
\mathrm{SMB}= & \frac{1}{3}\left(\mathrm{SMB}_{B / M}+\mathrm{SMB}_{\mathrm{OP}}+\mathrm{SMB}_{\text {Inv }}\right) \\
\mathrm{RMW}= & \frac{1}{2}(\text { Small Robust }+ \text { Big Robust })-\frac{1}{2}(\text { Small Weak }+ \text { Big Weak }) \\
\mathrm{CMA}= & \frac{1}{2}(\text { Small Conservative }+ \text { Big Conservative }) \\
& -\frac{1}{2}(\text { Small Aggressive }+ \text { Big Aggressive })
\end{aligned}
$$

\section{Appendix 3}

Table 8 in Appendix 3 shows the annual number of stocks in 25 Size-OP portfolios and 25 Size-Inv portfolios; however, there is no firms in several Size-OP portfolios (portfolio S1P2 of year 2010, portfolio S2P5 of year 2010 and 2012), and all the portfolios except one (portfolio S2P1 of year 2011) of year 2010 and 2011 have no more than five firms. In this case, we use the frame of six portfolios to test FF5F model on Chinese A-share

\begin{tabular}{|c|c|c|c|c|c|c|c|c|c|c|c|}
\hline & 2010 & 2011 & 2012 & 2013 & 2014 & & 2010 & 2011 & 2012 & 2013 & 2014 \\
\hline S1P1 & 1 & 5 & 27 & 38 & 167 & S1I1 & 155 & 131 & 130 & 152 & 149 \\
\hline S1P2 & 0 & 4 & 20 & 39 & 131 & $\mathrm{~S} 112$ & 82 & 67 & 89 & 111 & 112 \\
\hline S1P3 & 1 & 1 & 7 & 15 & 86 & $\mathrm{~S} 113$ & 44 & 56 & 72 & 70 & 80 \\
\hline S1P4 & 1 & 1 & 2 & 6 & 44 & $\mathrm{~S} 114$ & 32 & 52 & 49 & 52 & 56 \\
\hline S1P5 & 3 & 1 & 2 & 4 & 21 & $\mathrm{~S} 115$ & 19 & 90 & 100 & 64 & 64 \\
\hline S2P1 & 5 & 8 & 25 & 41 & 129 & S211 & 87 & 88 & 116 & 105 & 121 \\
\hline $\mathrm{S} 2 \mathrm{P} 2$ & 2 & 2 & 17 & 34 & 113 & $\mathrm{~S} 2 \mathrm{I} 2$ & 68 & 97 & 92 & 108 & 113 \\
\hline $\mathrm{S} 2 \mathrm{P} 3$ & 1 & 2 & 16 & 23 & 104 & $\mathrm{~S} 213$ & 60 & 56 & 69 & 93 & 97 \\
\hline S2P4 & 2 & 2 & 3 & 6 & 73 & $\mathrm{~S} 214$ & 50 & 48 & 73 & 63 & 68 \\
\hline S2P5 & 0 & 4 & 0 & 5 & 28 & $\mathrm{~S} 215$ & 66 & 108 & 88 & 83 & 62 \\
\hline S3P1 & 5 & 5 & 30 & 42 & 88 & S311 & 66 & 94 & 82 & 109 & 92 \\
\hline S3P2 & 3 & 8 & 31 & 42 & 107 & S312 & 81 & 89 & 101 & 99 & 101 \\
\hline S3P3 & 3 & 2 & 7 & 27 & 104 & $\mathrm{~S} 313$ & 71 & 69 & 98 & 86 & 100 \\
\hline S3P4 & 0 & 0 & 2 & 5 & 101 & S314 & 54 & 60 & 73 & 84 & 94 \\
\hline S3P5 & 1 & 3 & 3 & 5 & 45 & S315 & 60 & 82 & 86 & 73 & 75 \\
\hline S4P1 & 21 & 25 & 33 & 45 & 54 & S4I1 & 55 & 69 & 77 & 72 & 69 \\
\hline S4P2 & 18 & 21 & 37 & 46 & 83 & S412 & 60 & 90 & 99 & 83 & 95 \\
\hline S4P3 & 9 & 17 & 31 & 44 & 110 & $\$ 413$ & 81 & 84 & 84 & 106 & 95 \\
\hline S4P4 & 9 & 12 & 9 & 27 & 126 & S414 & 65 & 78 & 85 & 100 & 96 \\
\hline S4P5 & 2 & 4 & 5 & 10 & 69 & $S 415$ & 69 & 75 & 95 & 91 & 108 \\
\hline S5P1 & 27 & 35 & 40 & 41 & 42 & S511 & 35 & 41 & 55 & 51 & 59 \\
\hline S5P2 & 34 & 43 & 48 & 45 & 49 & $\mathrm{~S} 512$ & 64 & 90 & 71 & 83 & 66 \\
\hline S5P3 & 42 & 53 & 75 & 78 & 72 & $\mathrm{~S} 513$ & 77 & 112 & 113 & 98 & 91 \\
\hline S5P4 & 39 & 62 & 72 & 78 & 109 & S514 & 84 & 100 & 128 & 125 & 122 \\
\hline S5P5 & 31 & 53 & 46 & 61 & 166 & S515 & 71 & 53 & 72 & 94 & 124 \\
\hline
\end{tabular}
stock market instead of the 25 portfolios.

Table 8 Annual number of stocks in 25 value-weighted Size-OP portfolios and 25 value-weighted Size-Inv portfolios

This table presents the annual firm numbers in each 25 Size-OP portfolios and 25 Size-Inv portfolios from 2010 to 2014 in which $\mathrm{S}$ is the size group, $\mathrm{P}$ is the profitability groups, and I is the investment groups. For instance, S1P1 portfolio indicates the intersection of firms in the bottom $20 \%$ size quintile and firms in the bottom $20 \%$ OP quintile 


\section{Abbreviations}

B/M: Book-to-market; B/P: Book-to-price; FF: Fama and French; FF3F Model: Fama-French Three-Factor Model; FF5F Model: Fama-French Five-Factor Model; Inv: Investment; OP: Operating profitability; RMB: Renminbi or Chinese yuan; Size-B/M portfolios: Size and book-to-market portfolios; Size-Inv portfolios: Size and investment portfolios; Size-OP portfolios: Size and operating profitability portfolios; SSE: Shanghai Stock Exchange; SZSE: Shenzhen Stock Exchange

Funding

No funding is needed to be declared.

\section{Availability of data and materials}

All the original data on Chinese stock market is collected from Bloomberg, the construction of portfolios and factors and the regressions are done by ourselves. US data are downloaded directly from Kenneth R. French's website. Since the data amount is huge, it is available upon request.

\section{Authors' contributions}

WJ deals with the data, carries out research to investigate Fama-French Five-Factor Model on Chinese stock market, and writes the manuscript. JJL participates in the research and provides suggestions of modification. They both read and approve the final manuscript for publication.

\section{Competing interests}

The authors declare that they have no competing interests.

Received: 27 December 2016 Accepted: 12 April 2017

Published online: 24 April 2017

\section{References}

Carhart MM (1997) On persistence in mutual fund performance. J Financ 52:57-82

Chen C, Hu X, Shao Y, Wang J (2015) Fama-French in China: size and value factors in Chinese stock returns. University of Hong Kong Working Paper

Chiah M, Chai D, Zhong A (2015) A better model? An empirical investigation of the Fama-French five-factor model in Australia. In 2015 Financial Markets \& Corporate Governance Conference, p.

Cohen RB, Gompers PA, Vuolteenaho T (2002) Who underreacts to cash-flow news? Evidence from trading between individuals and institutions. J Financ Econ 66:409-462

Drew ME, Naughton T, Veeraraghavan M (2003) Firm size, book-to-market equity and security returns: evidence from the Shanghai Stock Exchange. Aust J Manag 28:119-139

Eun CS, Huang W (2007) Asset pricing in China's domestic stock markets: is there a logic? Pac Basin Financ J 15:452-480

Fairfield PM, Whisenant JS, Yohn TL (2003) Accrued earnings and growth: implications for future profitability and market mispricing. Account Rev 78:353-371

Fama EF, French KR (1993) Common risk factors in the returns on stocks and bonds. J Financ Econ 33:3-56

Fama EF, French KR (2006) Profitability, investment and average returns. J Financ Econ 82:491-518

Fama EF, French KR (2014) A five-factor asset pricing model, Fama-Miller Working Paper (September)

Fama EF, French KR (2015) International tests of a five-factor asset pricing model. Fama-Miller Working Paper

Haugen RA, Baker NL (1996) Commonality in the determinants of expected stock returns. J Financ Econ 41:401-439

Hou K, Xue C, Zhang L (2015) Digesting Anomalies: An Investment Approach. Review of Financial Studies 28(3):650-705.

Hung C-HD, Chen Q, Fang V (2015) Non-tradable share reform, liquidity, and stock returns in China. Int Rev Financ 15:27-54

Martinsa CC, Eid Jr W (2015) Pricing assets with Fama and French 5-Factor Model: a Brazilian market novelty. In XV Encontro Brasileiro de Finanças

Novy-Marx R (2013) The other side of value: the gross profitability premium. J Financ Econ 108:1-28

Richardson SA, Sloan RG (2003) External financing and future stock returns., Rodney L. White Center for Financial Research Working Paper

Titman S, Wei KJ, Xie F (2004) Capital investments and stock returns. J Financ Quant Anal 39:677-700

Wang Y, Di lorio A (2007) The cross section of expected stock returns in the Chinese A-share market. Global Financ 17:335-349

Zhang S, Xu J (2013) The fama-french three factors in the Chinese stock market

Zhan-hui C (2004) Cross-sectional variations and three factors asset pricing model: empirical evidences from China A share market. Chin J Manage Sci 6:3

\section{Submit your manuscript to a SpringerOpen ${ }^{\circ}$ journal and benefit from:}

- Convenient online submission

- Rigorous peer review

- Immediate publication on acceptance

- Open access: articles freely available online

- High visibility within the field

- Retaining the copyright to your article

Submit your next manuscript at $>$ springeropen.com 